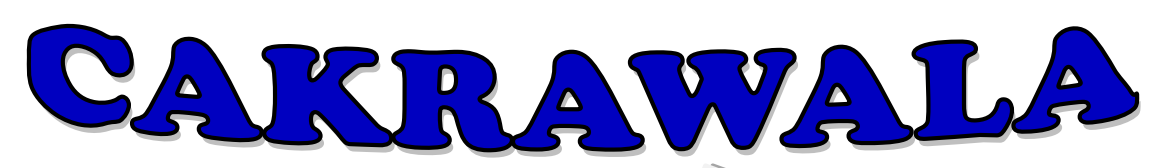

Management Business Journal [CM]-BJ] Volume 1 Nomor 1 Tahun 2018

\title{
ANALISIS PENERAPAN TEORI ANTRIAN DENGAN MENGGUNAKAN JALUR TUNGGAL PADA PENGAMBILAN DANA PENSIUN ASABRI DI PT POS INDONESIA (PERSERO) CABANG MANOKWARI
}

\author{
Hasna Wati Nahda ${ }^{1,}$ Dirarini Sudarwadi2, Y. Heri Saptomo ${ }^{3}$ \\ Universitas Papua ${ }^{1,2,3}$
}

Correspondence email: dirarinis@gmail.com

\begin{abstract}
ABSTRAK
Penelitian ini bertujuan untuk menjelaskan model sistem antrian jalur tunggal dan untuk mengetahui ukuran kinerja pelayanan yang optimal pada pengambilan dana pensiun Asabri di PT Pos Indonesia (Persero) Cabang Manokwari. Jenis penelitian deskriptif kuantitatifMetode analisis data yang digunakan adalah model antrian jalur tunggal yang artinya hanya ada satu jalur dan satu tahapan pelayanan yang harus dilalui penerima dana pensiun dalam pelayanan.

Hasil dari penelitian dengan menggunakan sistem antrian jalur tunggal yaitu menunjukkan karakteristik antrian diperoleh rata-rata antrian dalam sistem (LS) 15 orang, rata-rata yang antri dalam antrian (Lq) 14,0625 orang sedangkan peluang terjadinya 0 orang dalam sistem (Po) sebanyak $6,25 \%$. Rata-rata waktu menunggu dalam sistem (Ws) sebesar 0,5 menit atau 30 detik. Rata-rata waktu menunggu dalam antrian (Wq) sebesar 0,46875 menit atau 28,125 detik, tingkat kesibukan 93,75\% dalam perhitungan kinerja sistem antrian pada penelitian masih optimal sesuai dengan standar layanan yang telah ditetapkan.
\end{abstract}

\section{ABSTRACT}

This research aims to explain about the system of single track queue models and to know the measure of service performance on removal of pension funds Asabri in PT Pos Indonesia (Persero) Branch Manokwari. The types of this research is descriptive quantitative. Analytical method that used is a single track queue models that means only one and stage of service that should be passed by recipient of pension funds in the service.

The result of this research used of system single track queue up models that shown the characteristic of queuing by average queue system (Ls) 15 people. The average in queuing (Lq) 14,0625 people while the opportunity of people in system (Po) as much as 6,25\%. The average is waiting in the queue (Wq) of 0,46875 minutes or 30 seconds, $93,75 \%$ busyness level in the calculation of performance queuing system in this research is still optimal in reference with the predefined service standars.

Keywords: Queuing, theory, single, models, Papua. 


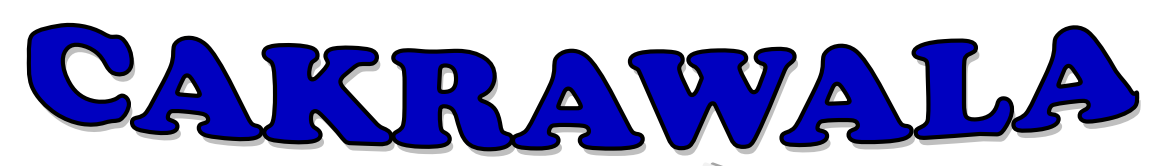

\section{Management Business Journal [CM:B, J] Volume 1 Nomor 1 Tahun 2018}

\section{PENDAHULUAN}

Manusia dalam kehidupan sehari-hari tidak lepas dari masalah antrian hampir semua orang pernah mengalami kegiatan antri. Fenomena ini menjadi kegiatan yang di anggap membosankan atau boros waktu karena tidak efisien. Akan tetapi baik suka atau tidak, menunggu atau mengantri sudah menjadi bagian dari kehidupan yang tidak bisa dihindari. Fenomena menunggu adalah hasil langsung dari keacakan dalam operasi sarana pelayanan. Situasi menunggu juga merupakan bagian dari keadaan yang terjadi dalam rangkaian kegiatan operasional yang bersifat random dalam suatu fasilitas pelayanan. Pelanggan datang ke tempat itu dengan waktu yang acak, tidak teratur, dan tidak dapat segera dilayani sehingga mereka harus menunggu cukup lama.

PT Pos Indonesia (Persero) Cabang Manokwari adalah suatu perusahaan yang bersifat jasa dimana tujuan dari PT Pos Indonesia (Persero) Cabang Manokwari adalah berorientasi pada kepuasan pelanggan. Pelanggan akan merasa tidak puas jika harus menuggu lama. Pelanggan menilai kualitas operasional sebuah perusahaan jasa adalah atas dasar lamanya waktu menunggu dan kecepatan sistem dalam memberikan pelayanan, antrian yang terlalu lama akan merugikan konsumen dan dapat mempengaruhi citra perusahaan (Septiyana, 2010).

Perusahaan jasa harus mampu memberikan pelayanan secara optimal karena jasa hanya dapat dirasakan langsung oleh konsumen.Kesan baik buruknya suatu pelayanan jasa dapat dilihat dari segi kinerja para karyawan dan jasa yang diberikan oleh sebuah perusahaan.Pelanggan berharap begitu mereka datang untuk mendapatkan pelayanan dengan segera dilayani.Akibatnya mereka harus menunggu gilirannya dilayani.Dilihat dari segi jasa kepuasan pelanggan dalam hal ini sangatlah penting didalam meningkatkan mutu perusahaan. Hal ini menyebabkan pihak manajemen dituntut untuk bagaimana cara agar konsumen tidak perlu menunggu lama, sehingga pemahaman mengenai teori antrian pun sangat 


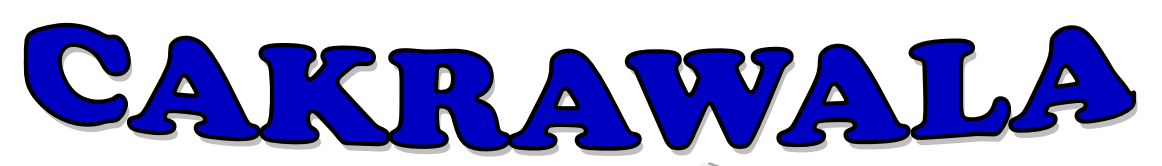

\section{Management Business Journal [CM:-BJ] Volume 1 Nomor 1 Tahun 2018}

dibutuhkan dalam megambil keputusan mengenai model antrian yang paling tepat untuk menunjang kelancaran operasi perusahaan (Dwi, 2014).

Antrian dapat dihindari apabila pihak-pihak yang terlibat mengetahui sampai dimana antri tersebut menguntungkan atau merugikan, yang sebenarnya peristiwa Page | - 23 antri ini tidak diinginkan oleh berbagai pihak yang berkepentingan. Permasalahan yang muncul adalah agar waktu yang tersedia digunakan secara optimal dan kedatangan pelanggan yang akan dilayani tidak mengelompok pada jam-jam atau hari-hari atau tanggal-tanggal tertentu. Sehingga dapat diketahui bersama bahwa kedatangan pelanggan tergantung pada keinginan dalam memenuhi kebutuhannya, dengan kata lain kedatangan pelanggan tidak dapat direncanakan. Namun, persamaan keinginan pelanggan untuk dilayani pada fasilitas di saat-saat tertentu itulah yang menimbulkan masalah antrian (Novela, 2013).

Teori antrian adalah ilmu pengetahuan tentang antrian, yang merupakan bagian penting bagi operasi dan merupakan alat yang sangat berharga bagi manajer operasi (Heizer dan Render, 2011) Umumnya, sistem antrian menganut prinsip yang datang duluan akan dilayani terlebih dahulu (first come, first served). Dalam hal ini pelayanan pada antrian akan sangat mempengaruhi pelanggan, maka perusahaan harus berupaya memberikan pelayanan yang optimal.

Menurut Heizer dan Render (2011) manajemen operasional adalah kegiatan yang berhubungan dengan penciptaan barang dan jasa melalui adanya pengubahan input dan output, dimana kegiatan tersebut terjadi di semua sektor organisasi. Berdasarkan pendapat-pendapat para ahli maka dapat disimpulkan bahwa manajemen operasional merupakan suatu kegiatan yang berhubungan dengan proses penciptaan barang dan jasa dalam suatu perusahaan untuk memenuhi kepuasan pelanggan.

Menurut Kotler (2009) mendefinisikan jasa sebagai setiap tindakan atau kegiatan yang dapat ditawarkan kepada pihak lain, pada dasarnya tidak berwujud 


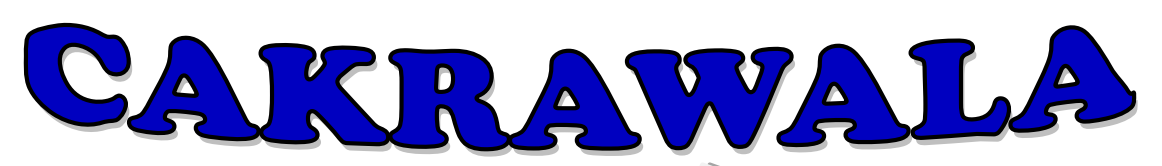

\section{Management Business Journal [CM:-BJ] Volume 1 Nomor 1 Tahun 2018}

dan tidak mengakibatkan kepemilikan apapun, produksi jasa mungkin berkaitan dengan produk fisik atau tidak.

Menurut Kotler (2009) mendefinisikan jasa sebagai setiap tindakan atau kegiatan yang dapat ditawarkan kepada pihak lain, pada dasarnya tidak berwujud Page | - 24 dan tidak mengakibatkan kepemilikan apapun, produksi jasa mungkin berkaitan dengan produk fisik atau tidak.Menurut Heizer dan Render (2006) antrian adalah ilmu pengetahuan tentang bentuk antrian dan merupakan orang-orang atau barang dalam barisan yang sedang menunggu untuk dilayani atau meliputi bagaimana perusahaan dapat menentukan waktu dan fasilitas yang sebaik-baiknya agar dapat melayani pelanggan dengan efisien. Teori tentang antrian diketemukan dan dikembangkan oleh A. K. Erlang, seorang insinyur dari Denmark yang bekerja pada perusahaan telepon di Kopenhagen pada tahun 1910.Erlang melakukan eksperimen tentang fluktuasi permintaan fasilitas telepon yang berhubungan dengan automatic dialing equitment, yaitu peralatan penyambungan telepon secara otomatis. Tujuan sebenarnya dari teori antrian adalah meneliti kegiatan dari fasilitas pelayanan dalam rangkaian kondisi random dari suatu sistem antrian yang berkaitan dengan produk fisik atau tidak.

Menurut Elida (2009) sebuah sistem antrian adalah suatu himpunan pelanggan, pelayan, dan suatu aturan yang mengatur kedatangan pada pelanggan dan pemrosesan masalahnya. Dalam sistem antrian terdapat tiga komponen karakteristik menurut Heizer dan Render (2006) yaitu: (a) karakteristik kedatangan atau masukan sistem; (b) karakteristik antrian; (c) karakteristik pelayanan. Berikut ini adalah penjabaran dari ketiga karakteristik sistem antrian.

Penelitian ini bertujuan untuk menjelaskan model sistem antrian jalur tunggal pada pengambilan dana pensiun Asabri di PT Pos Indonesia (Persero) Cabang Manokwari dan untuk mengetahui ukuran kinerja pelayanan sistem antrian yang optimal pada pengambilan dana pensiun Asabri di PT Pos Indonesia (Persero) Cabang Manokwari. 


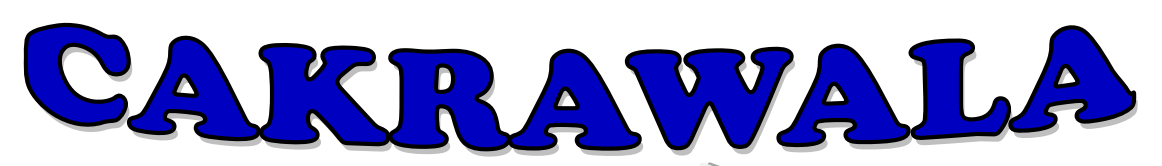

\section{Management Business Journal [CM:B, J] Volume 1 Nomor 1 Tahun 2018}

Penelitian ini diharapkan dapat bermanfaat bagi banyak pihak, antara lain: bagi akademik diharapkan penelitian ini dapat dijadikan sebagai referensi untuk melakukan pengembangan dan penelitian selanjutnya terkait masalah antrian, bagi perusahaan diharapkan hasil penelitian ini dapat memberikan kontribusi dalam Page |-25penentuan kebijakan di masa yang akan datang sehingga dapat mengoptimalkan kinerja perusahaan dalam mencegah dan mengurangi terjadinya antrian, bagi peneliti dapat digunakan sebagai tambahan wawasan dan pengalaman tentang masalah antrian terhadap penerapan teori antrian pada suatu perusahaan.

\section{METODE PENELITIAN}

Penelitian ini dilakukan di PT Pos Indonesia (Persero) Cabang Manokwari beralamat di jalan Yos Sudarso Sanggeng, waktu penelitian mulai tanggal 2-25 mei 2018. Pendekatan penelitian yang digunakan dalam penelitian ini adalah Pendekatan kuantitatif dan jenis penelitiannya, yaitu penelitian deskriptif. Penelitian deskriptif adalah penelitian yang dilakukan untuk mengetahui nilai variabel mandiri atau lebih (independen) tanpa membuat perbandingan, atau menghubungkan dengan variabel yang lain. Penelitian kuantitatif digunakan untuk menghitung jumlah jalur fasilitas yang optimal dan kinerja pelayanan fasilitas pada saat pengambilan dana pensiun Asabri di PT Pos Indonesia (Persero) Cabang Manokwari (Sugiyono,1999).

Populasi dalam penelitian ini sebanyak 548 penerima dana pensiun Asabri di PT Pos Indonesia (Persero) Cabang Manokwari. Teknik pengambilan sampel menggunakan teknik purposive sampling yaitu sampel yang diambil sesuai dengan kriteria pengambilan data yang dibutuhkan Adapun cara menentukan sampel dari penelitian ini menggunakan tabel penentuan jumlah sampel dari populasi tertentu yang dikembangkan dari Isaac dan Michael. Berdasarkan tabel penentuan jumlah sampel tersebut, dapat diketahui jumlah sampel dari populasi yang sudah diketahui yakni sebesar 182 penerima dana pensiun yang datang pada tanggal 3 Mei 2018 


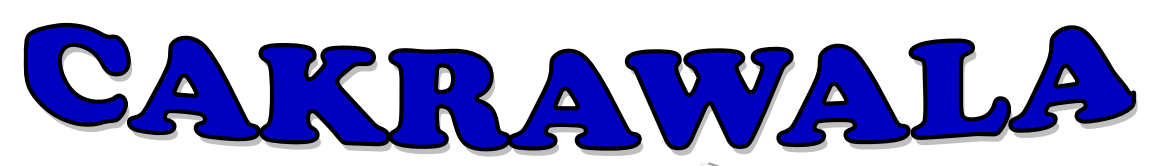

\section{Management Business Journal [CM:-BJ] Volume 1 Nomor 1 Tahun 2018}

dari jam 07.00 sampai dengan jam 13.00 dengan taraf kesalahan $10 \%$ (Sugiyono,1999)

Sumber dan teknik pengumpulan data yang akan dilakukan dalam penelitian ini adalah data Primer (hasil observasi langsung ke lokasi penelitian sebelum dan Page |-26pada saat penelitian berlangsung) dan data Sekunder (data yang diperoleh dari dokumen atau pustaka yang memiliki relevansi dengan penelitian).

Dalam proses pelayanan guna melayani para penerima dana pensiun Asabri, PT Pos Indonesia (Persero) Cabang Manokwari menggunakan Model Antrian Jalur Tunggal yang artinya hanya terdapat satu jalur fasilitas dan hanya ada satu tahapan pelayanan yang harus dilalui oleh para penerima dana pensiun untuk menyelesaikan pelayanan. Waktu yang dibutuhkan oleh para penerima dana pensiun bersifat acak (random). PT Pos Indonesia (Persero) Cabang Manokwari menerapkan pelayanan first-come, first server (FCFS) dimana perima dana pensiun yang datang pertama akan dilayani lebih dahulu. Untuk mengoptimalkan proses pelayanan dapat digunakan rumus antrian untuk Model A: M/M/1 (Heizer dan Render, 2005) sebagai berikut:

1. Jumlah penerima dana pensiun Asabri rata-rata dalam sistem. $L s=\frac{\lambda}{\mu-\lambda}$

2. Jumlah waktu rata-rata yang dihabiskan dalam sistem ( waktu menunggu ditambah waktu pelayanan ). Ws $=\frac{1}{\mu-\lambda}$

3. Jumlah unit rata-rata yang menunggu dalam antrian. $L q=\frac{\lambda^{2}}{\mu(\mu-\lambda)}$

4. Waktu rata-rata yang dihabiskan untuk menunggu dalam antrian.

$$
W q=\frac{\lambda}{\mu(\mu-\lambda)}
$$

5. Faktor utilisasi sistem. $\rho=\frac{\lambda}{\mu}$

6. Probabilitas terdapat 0 unit dalam sistem (yaitu unit pelayanan kosong).

$$
\text { Po }=1-\frac{\lambda}{\mu}
$$




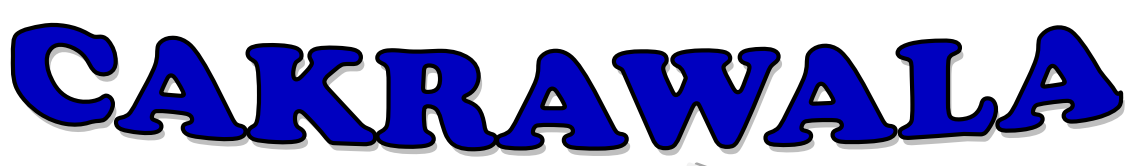

\section{Management Business Journal [CM:-BJ] Volume 1 Nomor 1 Tahun 2018}

\section{HASIL PENELITIAN}

\section{Struktur dan Jumlah Fasilitas Sistem Pelayanan}

Struktur sistem pelayanan di PT Pos Indonesia (Persero) Cabang Manokwari dalam proses pelayanannya dapat dilihat pada gambar berikut:

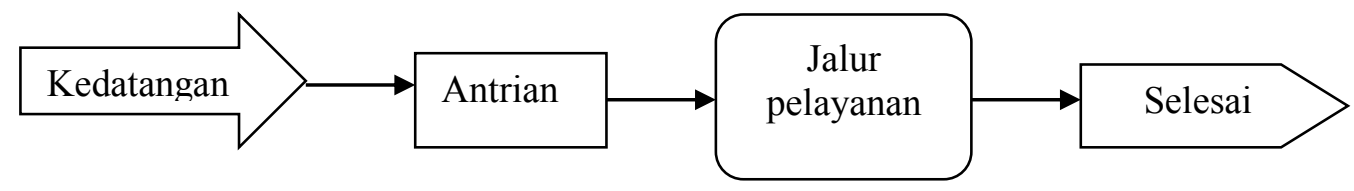

Sumber: Heizer dan Render (2006).

Gambar .1

Struktur Sistem Pelayanan

Penerima dana pensiun Asabri memasuki area pelayanan, kemudian membentuk suatu antrian dalam fasilitas yang ada. Penerima dana pensiun Asabri menunggu sampai tiba waktunya untuk mendapatkan pelayanan pada fasilitas, tahap ini merupakan waktu yang diperhitungkan sebagai waktu tunggu penerima dana pensiun Asabri di dalam sistem setelah proses transaksi selesai, penerima dana pensiun Asabri meninggalkan area (sistem). Dalam memberikan pelayanan waktuRkedatangan penerima dana pensiun berbeda-beda sehingga dapat menyebabkan terjadinya antrian.

PT Pos Indonesia (Persero) Cabang Manokwari beroperasi dalam pelayanan pembayaran dana pensiun Asabri memiliki jam pelayanan dari hari senin-jumat pukul 07.00-16.00 dan hari sabtu 07.00-15.00, dimana lamanya pelayanan loket atau server pembayaran dana pensiun Asabri terhadap penerima dana pensiun bersifat acak (random) tergantung pada banyaknya pembayaran pensiun yang diterima oleh penerima dana pensiun Asabri. Pola waktu kedatangan diuraikan menurut distribusi poisson yaitu kedatangan penerima dana pensiun lain tidak tergantung pada waktu atau tidak terbatas, dan pola waktu pelayanan yang diterapkan mengikuti distribusi eksponensial. Selain itu, disiplin pelayanan yang dilakukan adalah first come first served (FCFS) dimana penerima dana pensiun yang datang terlebih dahulu akan mendapatkan pelayanan pertama di loket atau server. 


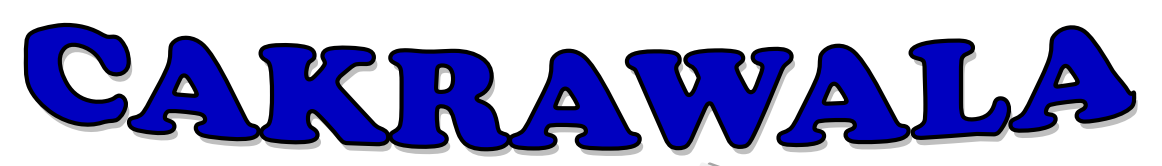

\section{Management Business Journal [CM:-BJ] Volume 1 Nomor 1 Tahun 2018}

\section{Tingkat Kedatangan Penerima Dana Pensiun dan Tingkat Pelayanan Fasilitas}

Tingkat kedatangan merupakan banyaknya penerima dana pensiun Asabri yang datang untuk mendapatkan pelayanan pada fasilitas, dinyatakan dalam berapa banyak penerima dana pensiun Asabri (orang) dalam periode waktu tertentu. Page |-28Tingkat kedatangan penerima dana pensiun diasumsikan mengikuti distribusi poisson yaitu kedatangan penerima dana pensiun Asabri lain juga tidak tergantung pada waktu (tidak terbatas) dan tingkat kedatangan setiap waktunya tidak sama karena masing-masing penerima dana pensiun Asabri mempunyai kebutuhan yang berbeda.

Jumlah penerima dana pensiun Asabri yang datang setiap waktunya dalam 1 hari berbeda-beda, Karena kebutuhan dalam mengambil dana pensiun. Berdasarkan data tingkat kedatangan penerima dana pensiun Asabri pada tanggal 3 mei 2018, maka dapat menghitung rata-rata tingkat kedatangan penerima dana pensiun Asabri per jam $(\lambda)$ dapat dicari dengan menggunakan rumus yaitu dengan menghitung total penerima dana pensiun dibagi dengan total jam kerja selama penelitian.

Tabel.1.

Rata-rata tingkat kedatangan penerima dana pensiun Asabri $(\lambda)$

\begin{tabular}{cccc}
\hline $\begin{array}{c}\text { Periode waktu } \\
\text { (jam) }\end{array}$ & $\begin{array}{c}\text { Jumlah kedatangan } \\
\text { penerima dana } \\
\text { pensiun Asabri } \\
\text { (orang) per jam }\end{array}$ & Total jam kerja & $\begin{array}{c}\text { Tingkat kedatangan } \\
(\lambda)\end{array}$ \\
\hline $07.00-08.00$ & 64 & 6 jam & 30,33 atau \\
$08.00-09.00$ & 28 & & 30 orang perjam \\
$09.00-10.00$ & 28 & & \\
$10.00-11.00$ & 24 & 6 jam & 30 orang perjam \\
$11.00-12.00$ & 33 & 5 & \\
$12.00-13.00$ & 182 & & \\
Total & 5
\end{tabular}

Berdasarkan informasi diatas dapat diketahui bahwa rata-rata tingkat kedatangan penerima dana pensiun perjam sebanyak 30 orang. Tingkat kemampuan (rata-rata) untuk melayani kebutuhan penerima dana pensiun Asabri 


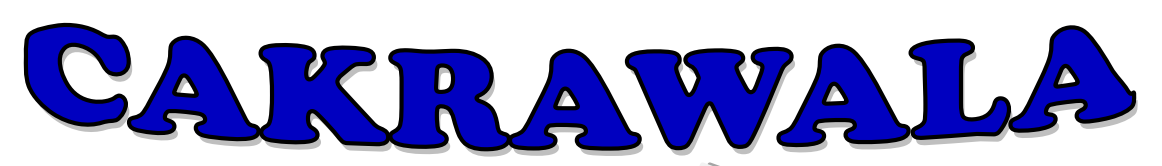

\section{Management Business Journal [CM:-BJ] Volume 1 Nomor 1 Tahun 2018}

dalam setiap kedatangannya disebut sebagai kemampuan pelayanan. PT Pos Indonesia (Persero) Cabang Manokwari memiliki standar waktu pelayanan 1 menit, sehingga dalam kemampuan melayani para penerima dana pensiun Asabri ini di dapat dari total rata-rata kedatangan penerima dana pensiun Asabri selama 6 jam Page | - 29 periode waktu penelitian. Berikut ini disajikan hasil perhitungan rata-rata tingkat pelayanan server/loket:

Tabel.2.

Rata-rata tingkat pelayanan $(\mu)$

\begin{tabular}{|c|c|c|c|c|c|}
\hline $\begin{array}{c}\text { Periode } \\
\text { waktu (jam) }\end{array}$ & $\begin{array}{c}\text { Jumlah } \\
\text { kedatangan } \\
\text { penerima dana } \\
\text { pensiun Asabri } \\
\text { (orang) }\end{array}$ & $\begin{array}{l}\text { Rata } \\
\text { pene } \\
\text { Asab }\end{array}$ & $\begin{array}{l}\text { latangan } \\
\text { pensiun } \\
\text { (orang) }\end{array}$ & Jam kerja & $\begin{array}{c}\text { Tingkat pelayanan } \\
(\mu)\end{array}$ \\
\hline $07.00-08.00$ & 64 & 10,67 & 11 & & \\
\hline $08.00-09.00$ & 28 & 4,67 & 5 & & \\
\hline $09.00-10.00$ & 28 & 4,67 & 5 & 6 jam & 32 orang \\
\hline $10.00-11.00$ & 24 & 4 & 4 & & Perjam \\
\hline $11.00-12.00$ & 33 & 5,5 & 6 & & \\
\hline $12.00-13.00$ & 5 & 0,83 & 1 & & \\
\hline Total & 182 & & 32 & & \\
\hline
\end{tabular}

\section{Karakteristik antrian di PT Pos Indonesia (Persero) Cabang Manokwari}

Teori antrian hendaknya dapat digunakan dalam keadaan perusahaan yang disesuaikan pada model yang ada.Hal ini disebabkan karena setiap model antrian memiliki karakteristik yang berbeda-beda.

Menurut model antrian yang ada, antrian di PT Pos Indonesia (Persero) Cabang Manokwari menggunakan model single channel single phase, yaitu model antrian yang menerapkan sistem antrian yang memiliki satu jalur antrian dan satu tahapan pelayanan, setelah mendapat pelayanan penerima dana pensiun tersebut meninggalkan area pelayanan. Berikut beberapa karakteristik dari sistem antrian yang ada pada PT Pos Indonesia (Persero) Cabang Manokwari: satu pelayanan dan satu tahap, jumlah kedatangan per unit waktu digambarkan oleh distribusi poisson dengan $\lambda=$ jumlah rata-rata tingkat kedatangan, waktu pelayanan eksponensial dengan $\mu=$ jumlah rata-rata orang yang dilayani atau tingkat pelayanan, disiplin 


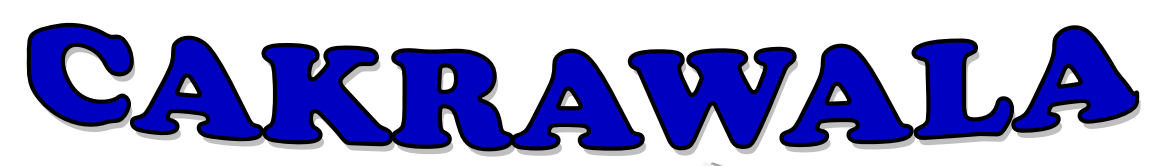

\section{Management Business Journal [CM:-BJ] Volume 1 Nomor 1 Tahun 2018}

antrian (FIFO (first in first out) adalah disiplin antrian yang digunakan, yaitu yang datang lebih dulu akan mendapatkan pelayanan terlebih dahulu), panjang antrian yang tak terbatas, atau kedatangan penerima dana pensiun yang secara acak, populasi yang dilayani tidak terbatas.

\section{Hasil Analisis Sistem Antrian dengan Model Jalur Tunggal (M/M/1)}

PT Pos Indonesia (Persero) Cabang Manokwari pada pengambilan dana pensiun Asabri menggunakan model antrian jalur tunggal $(\mathrm{M} / \mathrm{M} / 1)$ dimana hanya ada satu petugas untuk melayani penerima dana pensiun yang mengambil dana pensiunnya. Banyaknya penerima dana pensiun yang ingin mengambil dana pensiun Asabri ini seringkali menimbulkan antrian yang panjang dan membutuhkan waktu untuk mendapatkan pelayanan dari petugas pos, antrian ini terjadi karena hanya memiliki satu petugas pada loket/server pengambilan dana pensiun tersebut. Berikut ini disajikan hasil perhitungan analisis sistem antrian dengan menggunakan model antrian jalur tunggal (M/M/1). Perhitungan ini untuk mencari nilai Po, $\rho, L S$, Ws, Lq, dan Wq, dengan menggunakan rumus secara manual sehingga di dapat hasil perhitungan sebagai berikut:

\section{Tabel.3.}

Hasil perhitungan data

\begin{tabular}{|l|c|}
\hline \multicolumn{1}{|c|}{ Keterangan } & Hasil perhitungan \\
\hline$\wedge$ (Rata-rata Jumlah kedatangan) & 30 \\
$\mu$ (Rata-rata jumlah orang yang dilayani) & 32 \\
M (Jumlah jalur yang terbuka) & 1 \\
Po (Probabilitas terdapat 0 unit dalam sistem) & 0,0625 \\
P(Faktor utilisasi sistem) & 0,9375 \\
Ls (jumlah penerima dana pensiun Asabri rata-rata dalam sistem & 15 \\
Ws (Jumlah waktu rata-rata yang dihabiskan dalam sistem) & 0,5 \\
Lq (Jumlah unit rata-rata yang menunggu dalam antrian) & 14,0625 \\
Wq(Waktu rata-rata yang dihabiskan untuk menunggu dalam & 0,46875 \\
antrian & \\
\hline
\end{tabular}

\section{PEMBAHASAN}

Dari hasil analisis dengan menggunakan model antrian jalur tunggal dapat menunjukkan tingkat pelayanan yang sudah optimal, karena kurang dari 1 menit 


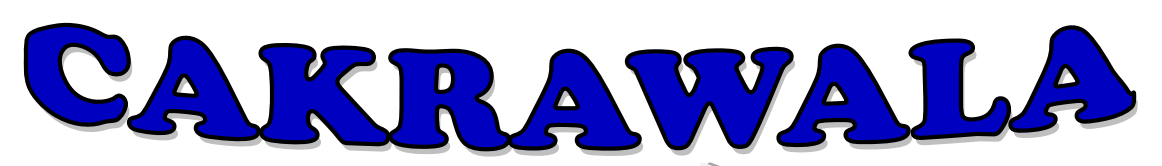

\section{Management Business Journal [CM:-BJ] Volume 1 Nomor 1 Tahun 2018}

waktu yang ditetapkan oleh PT Pos Indonesia (Persero) Cabang Manokwari. Hal ini terbukti berdasarkan perhitungan berdasarkan waktu pelayanan yang diberikan kepada para penerima dana pensiun Asabri memiliki waktu tunggu dalam antrian

kurang dari 1 menit dan waktu pelayanan dalam sistem adalah 0,5 menit, sehingga Page | - 31 dapat mengatasi tingkat kedatangan penerima dana pensiun Asabri.

Berdasarkan hasil analisis dengan menggunakan model antrian jalur tunggal dapat diketahui rata-rata tingkat kedatangan penerima dana pensiun Asabri 30 orang/jam dan rata-rata tingkat pelayanan 32 orang perjam penerima dana pensiun Asabri, serta dengan jumlah petugas sebanyak 1 orang terdapat hasil sistem perhitungan antrian sebagai berikut yaitu, probabilitas terdapat 0 orang dalam sistem antrian 0,0625 atau $6,25 \%$ yang artinya probabilitas 0 orang dalam sistem terdapat $6,25 \%$ menunjukkan tingkat terjadinya tidak ada orang dalam sistem masih rendah, rata-rata jumlah penerima dana pensiun Asabri dalam antrian (Lq) adalah 14 orang/jam, dan waktu rata-rata dalam sistem antrian (Ws) adalah 0,5 menit, waktu rata-rata dalam antrian (Wq) 0,46875 menit, serta tingkat kegunaan pelayanan loket/server adalah 93,75\% menunjukkan bahwa tingkat pelayanan yang diberikan kepada para penerima dana pensiun Asabri sangat baik.

Kualitas sistem operasi kerja pada antrian di PT Pos Indonesia (Persero) Cabang Manokwari dapat dikatakan sudah optimal karena masih sesuai dengan standar pelayanan yang di tetapkan pada PT Pos Indonesia (Persero) Cabang Manokwari yaitu 1 menit. Pada jumlah perhitungan sistem kinerja antrian kantor pos Indonesia Cabang Manokwari, telah melakukan fungsi operasi dengan baik yaitu terdapat waktu rata-rata penerima dana pensiun Asabri dalam antrian (Wq) adalah 0,46875 menit dan waktu rata-rata penerima dana pensiun Asabri dalam sistem (Ws) adalah 0,5 menit. Maka perhitungan diatas masih optimal karena kurang dari standar pelayanan PT Pos Indonesia (Persero) Cabang Manokwari dan dapat mengatasi tingkat kedatangan para penerima dana pensiun Asabri. 


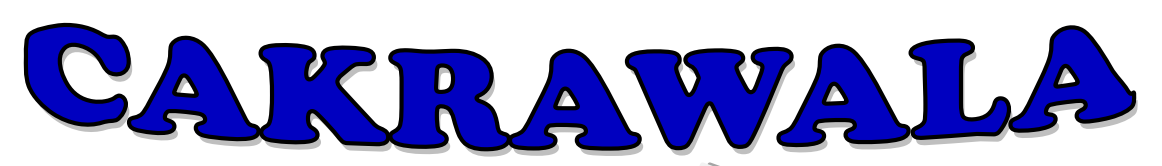

\section{Management Business Journal [CM:-BJ] Volume 1 Nomor 1 Tahun 2018}

\section{KESIMPULAN}

Kesimpulan yang dapat ditarik dari hasil analisa yang telah dilakukan dengan menerapkan teori antrian dengan model jalur tunggal pada PT Pos Indonesia (Persero) Cabang Manokwari adalah:Karakteristik antrian dari model antrian jalur Page | - 32 tunggal dengan satu tahap pelayanan di PT Pos Indonesia (Persero) Cabang Manokwari yang diperoleh selama penelitian menunjukkan bahwa: rata-rata yang antri dalam sistem (Ls) adalah 15 orang, rata-rata yang antri dalam antrian (Lq) adalah 14,0625 orang, peluang terjadinya 0 orang dalam sistem sebanyak $6,25 \%$, rata-rata waktu menunggu dalam sistem (Ws) adalah sebesar 0,5 menit atau 30 detik, rata-rata waktu menunggu dalam antrian (Wq) adalah sebesar 0,46875 menit atau 28,125 detik, tingkat kesibukan server sebesar 93,75\% yang berarti tingkat kesibukannya sangat tinggi tetapi operator server akan berganti setiap 2 jam.

Dari hasil perhitungan Kinerja sistem pelayanan pada PT Pos Indonesia (Persero) Cabang Manokwari telah memanfaatkan sistem kinerja secara optimal karena dalam pelayanan masih sesuai dengan standar pelayanan yaitu 1 menit. Sedangkan Dengan model antrian jalur tunggal dalam perhitungan kinerja antrian pada PT Pos Indonesia (Persero) Cabang Manokwari, terdapat waktu rata-rata penerima dana pensiun Asabri dalam sistem (Ws) adalah sebesar 0,5 menit dan waktu rata-rata penerima dana pensiun Asabri dalam antrian (Wq) adalah sebesar 0,46875 menit. Maka perhitungan kinerja sistem antrian pada penelitian masih optimal dikarenakan jasa petugas loket pada pengambilan dana pensiun Asabri mampu memberikan pelayanan sebesar 93,75\% dari kedatangan 182 penerima dana pensiun Asabri.

\section{REKOMENDASI}

Rekomedasi yang diberikan Bagi kantor pos tidak perlu menambah jalur pelayanan, karena dengan satu jalur pelayanan dapat memberikan pelayanan yang 


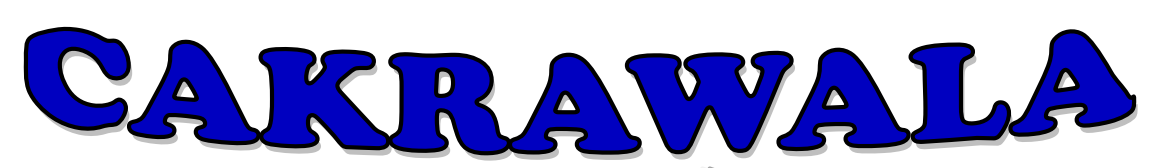

\section{Management Business Journal [CM:-BJ] Volume 1 Nomor 1 Tahun 2018}

optimal. Karena dengan satu jalur dan satu tahapan pelayanan petugas sudah dapat memberikan pelayanan yang baik.

Bagi peneliti selanjutnya diharapkan pada analisa data digambarkan secara rinci pengukuran waktu pelayanan secara nyata yang mengaitkan antara penerima dana Page | - 33 pensiun Asabri dan pelayanan. Hal tersebut dilakukan agar tidak terjadi penurunan kualitas kinerja pelayanan pada PT Pos Indonesia (Persero) Cabang Manokwari, sehingga dapat meminimalisir terjadinya pengurangan para penerima dana pensiun yang mengambil dananya pada kantor pos tersebut.

\section{DAFTAR REFERENSI}

Aditya, Indra Rizky. 2014. Permodelan sistem antrian pengambilan dana pensiun di kantor POS Cabang Gombong Kabupaten Kebumen menggunakan model antrian multiple server single phase. Jurnal mahasiswa statistic.vol 2, No. 5.

Alma, Buchori. 2000. Manajemen Pemasaran dan Pemasaran Jasa. Bandung: Alfabeta.

Aulele, Salmon Notje. 2014. Analisis Sistem Antrian Pada Bank MANDIRI Cabang Ambon. Jl. Ir. M. Putuhena. Jurnal Barekeng. Vol. 8, No. 1, $45-49$.

Heizer, Jay dan Barry Render. 2011. Operations Management.Tenth Edition. Pearson, New Jersey, USA

Kakiay, Thomas J. 2004. Dasar Teori Antrian Untuk Kehidupan Nyata. Yogyakarta : Andi.

Ma'arif dan Tanjung.2003. Manajemen Produksi dan Operasi. Edisi Revisi. Jakarta: Fakultas Ekonomi Universitas Jakarta.

Putri elida.2009. Simulasi Antrian dan Implementasinya.Tidak dipublikasikan.Skripsi.Medan : Universitas Sumatera Utara.

Sari, Novela Sekar. 2013. Analisis teori antrian pada Stasiun Pengisian Bahan Bakar Umum (SPBU) Gajah Mada Jember. Skripsi.Jember : Universitas Jember.

Septiyana, Dwi. 2010. Kinerja Pelayanan PT POS Indonesia Kabupaten Sragen.Skripsi. Surakarta: Universitas Sebelas Maret.

Sugiyono. 1999. Metode penelitian bisnis. Bandung: CV Alfabeta Bandung. 


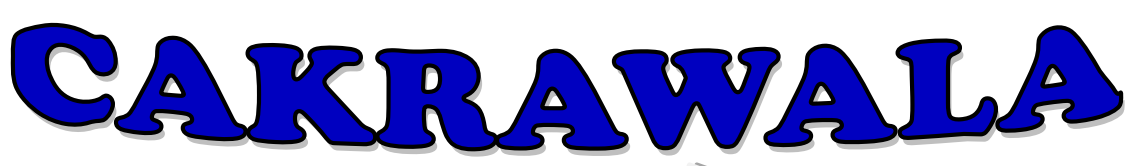

\section{Management Business Journal [CM:-B]] Volume 1 Nomor 1 Tahun 2018}

Suroso, siken.H. eddy soegiarto k. 2015.Antrian pada Stasiun Pengisian Bahan Bakar Umum (SPBU) 64 - 755 - 01 Blintut Barong Tongkok Kutai Barat.Jurnal ekonomi.Samarinda : Universitas 17 Agustus 1945.

Tampubolon, Manahan P. 2004. Manajemen Operasional. Jakarta : PT. Ghalia Indonesia.

Wulandari, dwi. 2014. Analisis Penerapan Teori Antrian Pada Supernarket Roxy Square-Mandiri Land di jalan Hayam wuruk Jember. Jurnal ekonomi. Jember: Universitas Jember.

PT Pos Indonesia.2018.http://www.posindonesia.co.id/index.php/pos-indonesia. diakses tanggal 26 mei 2018 jam 09.00 WIT.

Yudha, Eva Kharisma. 2011. Penerapan Teori Antrian Pada Sistem Pembayaran di TELISA JI. PB. Sudirman Jember. Skripsi. Jember: Universitas Jember 